\title{
Coaching for Communicative Competence: A Student-Focused Approach
}

\author{
Aidan Topping \\ Centre for Engineering Professional Practice and Engineering Education, University of Manitoba \\ Aidan.Topping@umanitoba.ca
}

\begin{abstract}
This paper focuses on instructor led, studentfocused coaching sessions undertaken in the senior (capstone) design classes at the University of Manitoba. The team-based design approach used in capstone courses allows students to work in a manner more closely reflecting industry practice; however, team writing does not allow for individualized scaffolding which could ensure each graduate meets the standard for communicative competence. Rather than allow students to rely on the team's collective communication skills, we developed an approach that incorporates individual coaching sessions at multiple stages in the writing process. These sessions require students to reflect upon their work, and allow them to discuss it in a meaningful way with the instructor. Doing so at various stages affords students the opportunity to engage in an iterative approach to developing communicative competence: applying what they learn, reflecting on their work, and discussing communicative gains and new methodologies.

While integrating individual coaching and directed instruction into the curriculum can be challenging, this paper demonstrates how student-focused coaching sessions provide a platform from which senior design students can increase both communicative competence and their value to industry as future engineers.
\end{abstract}

Keywords: Communication, engineering, education, coaching, capstone, student-focus

\section{INTRODUCTION}

Facilitating the communicative competence of graduating engineering students is an integral aspect of both C.E.A.B.'s mandate and the Faculty of Engineering's goals. As such, integrating a communications component into the senior design (capstone) courses, wherein students interact with industry clients on real-world problems, is essential. While students have access to feedback throughout the course from multiple sources, the main focus is on technical, design oriented work. This paper discusses the effectiveness of one approach to assessing and improving students' engineering related communicative abilities: individual coaching for improvement in the specific area of technical communication.

The team-based environment of capstone courses provides the students with the opportunity to learn and work in a manner more closely resembling industry workplaces, but also allows students with weaker communication skills to rely on their teammates' abilities. Team writing does not allow for the individualized scaffolding required for some students to achieve the expected level of communicative ability. Therefore, while the overall team's communicative competence may be highly rated, individuals who would benefit from more practice and direction in writing and presenting can be left behind. Furthermore, as Goldberg, Caves, and Reynolds observe, students typically "devote considerable effort to the design and development of their projects," but "are not as motivated to devote time and effort to writing" [1]. Another problematic aspect is that, as Wheeler and McDonald note, faculty members can resist the additional investment of time required to evaluate submissions specifically for writing quality, and may be uncomfortable evaluating skills that fall outside of their technical specialties [2].

How, then, can we as educators approach these problems to maximize both communicative growth and student buy-in? Paretti argues for the importance of establishing a milieu in which student and instructor exchange information, using a student-focused pedagogy to "transform the instructor from all-knowing lecturer to engaged participant and mentor" [3]. This reciprocal dialogue forms the basis of the approach we developed, which includes individual coaching sessions at multiple stages in the writing process to highlight areas for improvement for the participating students. We have seen that allowing students to direct the focus of these sessions, either explicitly or by asking a series of openended questions of them, leads to both increased student engagement with the writing process and improved integration of feedback (over formative feedback provided only via written comments and numerical grades). 


\section{BACKGROUND: THE INTEGRATION OF A WRITING INSTRUCTOR IN CAPSTONE COURSES}

In the mid-2000s, Dr. Anne Parker initiated a program through which designated "Communication Specialists" were embedded in several of the senior design courses at the University of Manitoba. The objectives were to increase the feedback provided in specific areas (writing and presentation skills), increase student access to communication resources and, as a result of meeting the first two goals, improve students' overall communicative competence and readiness for industry. Initially, several communication instructors were involved, and students received comments and grades via a variety of feedback forms. Over time, however, the program was streamlined, and continuity and marking reliability improved by using one dedicated instructor in all the participating courses. This led to improved tracking of recurrent communication issues and the creation of resources aimed at the specific cohort of students. Additionally, these resources are easily adaptable to deal with new or changing trends demonstrated in problematic submissions. The rubrics used to provide initial feedback to students (documented by Parker and Topping) evolved such that 1) accessibility was improved based on patterns of student usage, 2) both numerical grades and written comments were given, and finally, 3) students were placed on a spectrum of competency, using clear descriptors delineating how to reach the next level of competency [4].

Additionally, the format of instructor/student meetings has evolved. In the early years of this integrated program, students' questions were often focused on why or how they lost marks, but as the rubrics changed, so too has the student/instructor dialogue. Initially, the demand for numerical breakdowns and justifications, combined with explicit requests along the lines of "Show me how to get $100 \%$," frequently lead to the session being reduced to a grading question and answer period. However, using a recursive approach similar to that used to develop the rubrics, we have been able to shift the focus of these meetings. Since the processes of engineering design and technical writing contain many of the same elements (an initial stage of creativity, improvement via multiple iterations, and the central idea that a perfect solution remains impossible) [2], it is particularly fitting that the coaching sessions now support more open-ended discussions of student-specific issues.

A brief note concerning terminology: the term "coaching" is used throughout this paper; for consistency, "mentoring" is not used. While authors such as Stowers and Barker [5] and Pembridge and Paretti [6] make distinctions between the two terms, a semantic analysis is beyond the scope of this paper. Therefore, "coaching" in the present context refers to the improvement of students' communicative competence "through observation, discussion, and follow up" [5], but it also denotes a relationship of a more senior and experienced professional with a less experienced person engaged in a learning process [6].

\section{COACHING SESSIONS}

The coaching sessions, or conferences, held with students are primarily facilitated by the instructor's continued presence in the classroom. Not only does this provide the instructor with a baseline of knowledge on the projects on which the capstone students are working, but it also establishes the instructor as a fixture in the course. Experience has shown that the more active the instructor's participation in all aspects of the class, the higher the likelihood that students will attend individual conferences. Coaching sessions are not a mandatory part of the capstone course, though they are highly recommended, so student initiative is required. However, the majority of students who participate do so repeatedly.

\subsection{The Importance of Patterning}

Students are able to request a coaching session at any time in the communicative process: after completing a draft, but before submission; after receiving feedback to discuss comments and, if the submission does not mark their first conference, growth from previous assignments; prior to an oral presentation to review organization; or even to address audience analysis given the diverse set of stakeholders in a capstone project.

Regardless of the specific visit's purpose, though, we make every effort to maintain a sense of consistency. Conferences are not an editing meeting, and the communications instructor is not a proofreader; students can therefore expect to be active participants in the sessions. Establishing an open dialogue around individual communicative skills and the potential for skill development early in the course engages students in the process of creating their own learning plans [8]; guiding a student toward the discovery of improved methods of communication rather than immediately showing him or her the "right way" both requires and allows the student to remain engaged in the process of his or her own learning.

Once student engagement is established, future conferences follow the general pattern of discussion of communicative gains, new skills and approaches, and, following student application of what he or she has learned, reflection on the work. This process gives students the opportunity to hone their skills, but also presents writing as a process, and one that mimics the design process to a large degree [2]. Forging connections between what they tend to view as the more important 
work of engineering design and the "other" represented by the softer skills gives students permission to approach writing and presenting with the same rigor as they do their technical work.

\subsection{Coaching Session Protocol}

Each coaching session is unique and directed toward the individual student's communicative needs. There are, however, recurring themes and observations that have led to a certain protocol for the conferences. We have not created a template agenda or documented any firm requirements for the meetings because the chance of a student raising an unexpected problem or needing guidance in a new area is always there. The purpose of the coaching sessions is to meet each student where he or she is, and address the most essential communicative needs. Not insignificantly, "most essential" encapsulates not only what the instructor believes to be the student's most pressing communicative need, but, and most importantly, what the student feels is his or her most important communicative challenge. Student engagement is at the core of the entire program, and were we to rely on a more didactic process, reflective of a more traditional classroom atmosphere, we would lose much of the inclusive and dialogic process that leads to students making guided communicative discoveries of their own.

One common approach for a first coaching session requires the instructor, regardless of the detail included in the submitted work, to ask an open-ended question to prompt the student to speak broadly about his or her project. A question such as 'I'm interested in your topic; can you set up the project for me? Tell me what you're working on" can often elicit a much clearer explanation of the project's purpose than that written by the students. Reassuring them that clarity takes precedence over the type of (often confusing) academic-speak they frequently believe instructors want from them gives them permission to begin to communicate from a perspective of sharing information rather than impressing upon the reader the sheer volume of research completed, or number of academic-sounding words used.

Moving forward in the coaching process, experience has shown that rather than pointing out errors in construction, which can act to close students off from the dialogic process, asking what they were trying to convey in a certain passage allows them to rethink the idea and attempt an explanation in a more informal setting with lower stakes. Questions such as "how could you explain it differently in the text, then?" prompt them to reform the initial construction more formally once they've proven their understanding. Furthermore, this kind of approach throughout the writing process is valuable because it allows students to "experience and understand the material in a direct and personal way" [2], via their own work rather than through arbitrary writing samples that may hold little meaning or value for them. The discoveries are there for them to make, with our guidance, rather than handed to them out of context.

A student-focused pedagogy such as this provides the opportunity to establish relationships with students that go beyond assigning grades. The frequency with which many take advantage of the coaching sessions allows the instructor to lead the dialogue toward the one or two most pressing communicative needs, which gives the student time to reflect, learn, and adapt accordingly before moving on to another, less pressing communicative issue. By not overwhelming the student with large amounts of feedback at any one time, as is often the case when papers are returned after grading, and by dealing with communication as a process, one which must be designed to meet a particular set of expectations, students have proved open to raising their own communicative concerns and implementing constructive feedback.

In the capstone design classes, those expectations are set by multiple stakeholders, and once students can clearly present information, they can begin the next step in the process: ensuring they meet the specific informational needs of their distinct audience. The value of capstone courses is that they allow students to begin the process of bridging the gap between academia and industry. Part of the value of the coaching sessions is found in guiding students beyond merely producing a report that mimics a workplace product and toward engaging "realistically in the workplace practice of creating texts to meet real needs" [3].

Interestingly, the one aspect of these sessions that we found required diligent enforcement of the type we generally avoid, was time limitations. Experience has shown that a student discussing his or her own work in an environment such as we provide likes to continue to discuss that work, and thus coaching sessions tend to run long. The very real problem this creates is a lack of time: one instructor can only see so many students in a day. Given the coaching sessions are voluntary, we have yet to see 100 percent compliance. However, one capstone course reached 80 percent compliance, which proved to be the maximum that could be accommodated. Resources are a very real problem with such an intensive approach, and as effective as the coaching sessions have been, there are other, more time-efficient strategies that can be implemented.

\section{THE QUESTION OF RESOURCES}

The project-specific, industry-driven nature of the approach we take to improving writing skills in capstone classes would be most effectively and efficiently implemented with a dedicated instructor focused on the specific need of industry bound students. However, 
smaller educational institutions, or those with fewer resources to devote to the communicative components of technically focused design courses, could begin to integrate small changes with larger potential.

Rather than bring in an occasional lecturer/grader from the English department, which addresses neither, as Parker notes, the situational requirements of technical engineering writing [7], nor the consistent patterning that leads to student acceptance, instructors with fewer available resources can begin to address individualized feedback in a number of ways.

First, rather than assess written assignments solely on the basis of technical content, a portion of the overall grade can be assigned to the assessment of the quality of the writing. This category needn't be grammar focused, but can cover such elements as overall organization, formatting, general readability, and industry applicability. While we have integrated this feedback into team-based courses via individual meetings and draft reviews, the format could be used equally effectively in a course based on individual assignments. Omitting the individual conferences would necessarily reduce the student/instructor dialogue; however, if one or two elements were addressed each assignment with constructive comments for improvement, communicative gains could still be made.

Secondly, teaching assistants could be used more widely than is typical in engineering courses. A teaching assistant with suitable experience could take on some coaching duties, even incorporating tutorials with small groups of students to address overall trends noted in assessments.

Finally, thorough communication rubrics could be used in addition to the more technical feedback given. While rubrics do require an initial expenditure of resources to create, they allow an instructor to provide a level of formative feedback to students that written comments do not, given the time required to formulate individualized written feedback.

\section{CONCLUSIONS}

Like engineering design and writing, curriculum development is an iterative process. Our effective model for student-focused coaching sessions developed over the course of multiple terms, and we both expect and hope that it continues to evolve based on student need and emerging communicative trends in our increasingly global industry. While the number of instructors initially involved and the evolution of the approach itself made it difficult to fully track the success of the program in the earlier years, anecdotal evidence and student feedback to date point to both a positive reception and gains in students' communicative competence. Recent grade trends show the majority of students improving over the course of their capstone work, displaying communicative gains with each report. Moving forward, we hope to track students' development in a more detailed manner, and will continue to adjust our resources as student needs dictate.

While industry needs well-trained engineering graduates with strong communicative competence, how we as educators get each student to that point is down to both of us: educators and students. We must continue to integrate a guided, student-focused dialogue to assess what they need in order to fulfill their communicative potential.

\section{Acknowledgements}

The author gratefully acknowledges the financial support of Mr. Robert A. Kennedy. Also, the support from, and continuing work of, Dr. Anne Parker and Dr. Paul Labossiere has been invaluable.

\section{References}

[1] Richard Goldberg, Kevin Caves, and Julie A. Reynolds. "Improving the quality of writing in a capstone engineering design course," in Proc. ASEE American Society for Engineering Education Conf., (Vancouver, B.C.;26-29 June 2011), 11 pp., 2011.

[2] Edward Wheeler and Robert L. McDonald, "Writing in engineering courses," Journal of Engineering Education, vol. 89, pp. 481-486, 2000.

[3] Marie C. Paretti, “Audience awareness: Leveraging problem-based learning to teach workplace communication practices," IEEE Transactions on Professional Communication, vol. 49, no. 2, pp. 189-198, June 2006.

[4] Anne Parker and Aidan Topping, "Designing rubrics for communication courses in engineering: A work in progress," Proc. CEEA Canadian Engineering Education Conf., CEEC13 (Montreal, Q.C.; 17-20 June 2013), 6 pp., 2013.

[5] Robert H. Stowers and Randolph T. Barker, "The coaching and mentoring process: The obvious knowledge and skill set for organizational communication professors," Journal of Technical Writing and Communication, vol. 40. No. 3, pp. 363-371, 2010.

[6] James J. Pembridge and Marie C. Paretti, "Work in progress - A comparison of mentoring functions in capstone courses across engineering disciplines," Proc. ASEE/IEEE Frontiers in Education conf. IEEE11 (Rapid City, S.D.; 12-15 October 2011.

[7] Anne Parker, "Preparing engineering students for the communicative exigencies of the profession: Exploring the future of technical communication in engineering 
education." Proc. CEEA Canadian Engineering Education Conf., CEEC12 (Winnipeg, M.B.; 17-20 June 2012), 5 pp., 2012.

[7] Daniel Harvey, "The writing conference; Suggestions from writing studies research," Writing Across the Curriculum, March 2012. Available as of May 9, 2016 from http://wac.ctl.ualberta.ca/ /media/wac/quick_guides/WAC_ The_Writing_Conference.pdf 